\title{
Comparative Study on Pantothenic Acid Separation by Reactive Extraction with Tri-n-octylamine and Di-(2-ethylhexyl) Phosphoric Acid
}

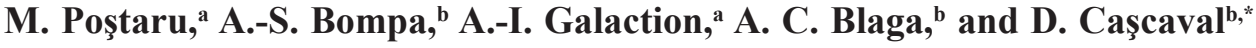 \\ aDepartment of Biomedical Science, Faculty of Medical Bioengineering, \\ "Grigore T. Popa" University of Medicine and Pharmacy, \\ M. Kogălniceanu 9-13, 700454 Iasi, Romania \\ doi: 10.15255/CABEQ.2015.2194 \\ bDepartment of Biochemical Engineering, Faculty of Chemical \\ Engineering and Environmental Protection, "Gheorghe Asachi" \\ Technical University, D. Mangeron 73, 700050 Iasi, Romania \\ Original scientific paper \\ Received: February 19, 2015 \\ Accepted: February 26, 2016
}

\begin{abstract}
The mechanism of reactive extraction of pantothenic acid with tri- $n$-octylamine and di-(2-ethylhexyl) phosphoric acid was analysed for three solvents in the presence or absence of 1-octanol. In the absence of 1-octanol, the stoichiometric ratio between the solute and tri- $n$-octylamine was 1:1 for dichloromethane, $1: 2$ for butyl acetate, and 1:4 for $n$-heptane. In the presence of 1-octanol, the formation of aminic adducts was restricted, the stoichiometries for the interfacial reaction between the acid and tri- $n$-octylamine becoming 1:1 for dichloromethane and butyl acetate, 1:2 for $n$-heptane. A similar effect has been observed for extraction with di-(2-ethylhexyl) phosphoric acid, the structure of the interfacial compound being changed for $n$-heptane and butyl acetate from $\mathrm{HAE}_{2}$ in the absence of 1-octanol to HAE by addition of this alcohol. The highest extraction constants were obtained when extractant associates were formed. However, when the extraction mechanism was the same, the increase in organic phase polarity influenced positively the value of extraction constant.
\end{abstract}

Key words:

pantothenic acid, reactive extraction, interfacial mechanism, extraction constant, tri- $n$-octylamine, di-(2-ethylhexyl) phosphoric acid

\section{Introduction}

Pantothenic acid, also known as vitamin B5, is a water-soluble vitamin involved in the conversion of carbohydrates into glucose needed to produce energy. ${ }^{1}$ From the chemical point of view, pantothenic acid is the amide of pantoic acid with $\beta$-alanine (Figure 1).<smiles>CC(C)(CO)C(O)C(=O)NCCC(=O)O</smiles>

Fig. 1 - Chemical structure of pantothenic acid

Vitamin B5 was isolated from yeast in 1933, and a few years later from liver, by R.J. Williams. The main role of pantothenic acid in cells is the synthesis of coenzyme A, as well as the synthesis and metabolism of proteins, carbohydrates and fats. Regarding the human body, this compound is involved in the health of the digestive, nervous, circu-

"Corresponding author: e-mail: dancasca@yahoo.com, dancasca@ch.tuiasi.ro; tel./fax: 0040232271311. latory, and skeletal systems, skin and hair, as well as in the synthesis of hormones (insulin, adrenaline). It also plays an important role in increasing the immunity of the human body.

Generally, pantothenic acid is obtained from natural sources (bread yeast, mushrooms, cereals, eggs, peanuts, soybeans, lentil, liver of various animals or birds, etc.). From these materials, this compound can be obtained by extraction with aqueous solvents, in weak acidic medium $(\mathrm{pH}=4-5)$ at elevated temperature $\left(80-95^{\circ} \mathrm{C}\right)$, with or without prior enzymatic hydrolysis of the natural compounds formed by the acid (usually, the enzymatic complex containing papain is used for this purpose). ${ }^{2,3}$ Pantothenic acid can also be obtained by chemical synthesis. ${ }^{4}$ An efficient alternative is its biosynthesis by microorganisms, due to the reduction of the required process steps and consumption of materials and energy. The biochemical synthesis uses Brucella abortus, Azotobacter vinelandii, Escherichia coli, Fusarium oxysporum microorganisms, the main nutrients of the cultivation media being glucose and ammonium inorganic or organic salts. ${ }^{4-7}$

The separation of pantothenic acid from natural extracts or biosynthesis media can be carried out by 
crystallization, ion exchange, and chromatography, but with rather low efficiency and significant material and energy costs. ${ }^{7-10}$

The separation by physical extraction constitutes a viable solution in many technologies, being technically accessible and offering high efficiency. However, its application is limited for the ionizable compounds, namely the carboxylic acids, due to their low solubility in usual organic solvents. Pantothenic acid is soluble in water-miscible solvents (ethanol, 1-pentanol, acetic acid, dioxane), and moderately soluble in benzene, chloroform, diethyl ether, ethyl acetate. ${ }^{11}$ For these reasons, either the physical extraction cannot be applied or it allows reaching rather low distribution coefficients between the aqueous and organic phases, being inefficient at larger scale.

The performance of extraction processes can be improved by adding an extractant into the organic phase, which can react with the solute to form a hydrophobic compound. Generally, this separation method, called reactive extraction, uses extractants (organophosphoric compounds, high molecular weight amines or macrocyclic compounds) to separate some natural carboxylic acids. ${ }^{12-14}$ Because the chemical structure of pantothenic acid contains both acidic and basic groups, the reactive extraction could become possible with two different extractants: one of the high molecular weight amine type, and the other from the organophosphoric acid compounds category.

In this context, this work investigates comparatively the reactive extraction of pantothenic acid with tri- $n$-octylamine (TOA) and, respectively, with di-(2-ethylhexyl) phosphoric acid (D2EHPA) dissolved in three different solvents ( $n$-heptane, butyl acetate, and dichloromethane) in the presence or absence of 1-octanol as phase modifier. Therefore, the influences of extraction system characteristics (extractant type, solvent polarity, 1-octanol addition) and operating conditions ( $\mathrm{pH}$-value of aqueous phase, extractant concentration) on the efficiency of extraction have been analysed, and the mechanism of interfacial reaction has been discussed.

\section{Materials and methods}

The experiments were carried out using an extraction column with vibratory mixing, which offers high interfacial area and the possibility of reaching rapidly the equilibrium state. The laboratory equipment has been described in detail in previous papers, ${ }^{12,14}$ which consists of a glass column with internal diameter of $36 \mathrm{~mm}$ and height of $250 \mathrm{~mm}$, provided with a thermostatic jacket where the thermal agent (water and ethylene glycol mixture) is circulated at $25{ }^{\circ} \mathrm{C}$. The phases were mixed by means of a perforated disk with $45 \mathrm{~mm}$ diameter and $20 \%$ free section. The vibrations had a frequency of $50 \mathrm{~s}^{-1}$ and amplitude of $5 \mathrm{~mm}$. The perforated disk position was maintained at the initial contact interface between the aqueous and organic phases. The extraction time was 1 minute. The resulting emulsion was broken in a centrifugal separator at $8000 \mathrm{rpm}$.

The initial pantothenic acid (Fluka, $\geq 99.9 \%$ ) concentration in aqueous solution was $5 \mathrm{~g} \mathrm{~L}^{-1}$ $\left(2.28 \cdot 10^{-2} \mathrm{M}\right)$. The reactive extraction was carried out with three solvents possessing different dielectric constants, namely $n$-heptane (Merck, $\geq 99 \%$ ) (dielectric constant 1.90 at $25^{\circ} \mathrm{C}$ ), ${ }^{11}$ butyl acetate (Flu$\mathrm{ka}, \geq 99 \%$ ) (dielectric constant of 5.01 at $\left.25^{\circ} \mathrm{C}\right),{ }^{11}$ and dichloromethane (Fluka, $\geq 99.9 \%$ ) (dielectric constant 9.08 at $25{ }^{\circ} \mathrm{C}$ ). ${ }^{11} 1$-Octanol (Fluka, $\geq 99.9 \%$ ) (dielectric constant 10.3 at $\left.25^{\circ} \mathrm{C}\right)^{11}$ was dissolved into the solvents mentioned above, its volumetric fraction being 0.20 .

The two extractants, TOA (Sigma, $\geq 98 \%$ ) and D2EHPA (Fluka, $\geq 95 \%$ ), were dissolved separately in the organic phase. The extractants concentrations in organic phase varied between 5 and $80 \mathrm{~g} \mathrm{~L}^{-1}$ (0.014 to $0.23 \mathrm{M}$ for TOA, respectively 0.015 to $0.24 \mathrm{M}$ for D2EHPA). The volumetric ratio of aqueous and organic phases was $1(20 \mathrm{~mL}$ of each phase).

The $\mathrm{pH}$ value of the initial aqueous solution was varied between 1 and 7 . The $\mathrm{pH}$ adjusted with a solution of $3 \%$ sulphuric acid or $3 \%$ sodium hydroxide, depending on the prescribed $\mathrm{pH}$-value. The $\mathrm{pH}$-values were determined using a digital $\mathrm{pH}$-meter of Consort C836 type, and were recorded throughout each experiment. Any $\mathrm{pH}$ change was recorded during the extraction experiments.

The extraction process was analysed by means of the extraction yield and distribution coefficient. For calculating these parameters, the pantothenic acid concentrations in the initial aqueous solution and in the raffinate were measured, and the mass balance was used for the entire extraction system. For this purpose, the HPLC method with concentration gradient was used (Dionex Ultimate 3000, Acclaim PolarAdvantage column type II (PA2), with a diameter of $4.6 \mathrm{~mm}$, length of $150 \mathrm{~mm}$, particles diameter of $5 \mu \mathrm{m}$ ). The equipment was provided with UV-VIS detector with diode array DAD-3000. The injection volume was $20 \mu \mathrm{L}$. The mobile phase consisted of acetonitrile (A) and phosphate buffer ( $\mathrm{pH}=3.2$, phosphoric acid) (B). The gradient was $0-35 \% \mathrm{~A}$ in the first 14 minutes, at a flow rate of $1 \mathrm{~mL} \mathrm{~min}^{-1}$. Analyses were carried out at temperature of $25^{\circ} \mathrm{C}$.

Each experiment was repeated two or three times for identical conditions, using the average 
value of the considered parameters. The maximum experimental error was $\pm 4.83 \%$.

\section{Results and discussion}

\section{Reactive extraction in the absence of 1-octanol}

Pantothenic acid has a rather complex structure, possessing one carboxylic and one amide group that could react with the two considered extractants. Regardless of the extractant type, because the solubility of solute and, respectively, extractant in the opposite phase is very low or zero, ${ }^{11,15}$ it can be assumed that the reactive extraction of pantothenic acid occurs by the formation of a strong hydrophobic compound at the interface between the aqueous and organic phases. The mechanism and kinetics of the interfacial reaction and the optimum operating conditions depend on the extractant type and polarity of the organic phase.

Therefore, similar to the extraction of other organic acids, the carboxylic group of pantothenic acid is involved in the process of reactive extraction with TOA (E). The interfacial interactions between solute and extractant could be of the hydrogen-bonding type if the pantothenic acid is undissociated in the aqueous phase, or of the ionic type if the acid is partially dissociated:

$$
\begin{gathered}
\text { R-CO-NH- }\left(\mathrm{CH}_{2}\right)_{2}-\mathrm{COOH}_{\text {(aq) }}+\mathrm{n} \mathrm{E}_{\text {(org) }} \rightleftarrows \\
\rightleftarrows \text { R-CO-NH- }\left(\mathrm{CH}_{2}\right)_{2}-\mathrm{COOH} \cdot \mathrm{E}_{\mathrm{n}(\mathrm{org})}
\end{gathered}
$$

Furthermore, depending on the structures of system components and solvent polarity, the acidic or aminic adducts could be formed at the interface. However, as it was observed for the reactive extraction of other carboxylic acids, ${ }^{13,15,16}$ due to the steric hindrance induced by the voluminous molecule of pantothenic acid and its initial concentration which is lower compared to that of TOA, the formation of acidic adducts at the interface is hindered. Therefore, the interfacial compound could be of ammonium salt type as a result of neutralization of the solute carboxylic group with one extractant molecule, or of aminic adducts type, for $n \geq 2$. The formation of these molecular associations is more pronounced in solvents with low dielectric constant and improves the hydrophobicity of the interfacial compound. ${ }^{17}$

Because pantothenic acid contains one basic group, namely carbonyl from amide group, it can react also with acidic extractants, including D2EHPA (HP). Similar to the extraction of other basic compounds, ${ }^{18,19}$ in this case, the reactive extraction occurs by means of an interfacial reaction of ion-exchanging type, which requires the solute to be in protonated form in the aqueous phase (carbonyl oxygen at low $\mathrm{pH})$ :

$$
\begin{aligned}
& \mathrm{R}-\mathrm{COH}^{+}-\mathrm{NH}-\left(\mathrm{CH}_{2}\right)_{2}-\mathrm{COOH}_{(\mathrm{aq})}+\mathrm{n} \mathrm{HP}_{(\mathrm{org})} \rightleftarrows \\
& \rightleftarrows \mathrm{R}-\mathrm{COH}^{+}-\mathrm{NH}-\left(\mathrm{CH}_{2}\right)_{2}-\mathrm{COOH}^{-} \text {-(n-1)HP }{ }_{\text {(org) }}+\mathrm{H}^{+} \text {(aq) }
\end{aligned}
$$

For the same reason as discussed above, the formation of the adducts containing many molecules of pantothenic acid is also hindered in the extraction with D2EHPA.

The dependence between the pantothenic acid extraction yield and $\mathrm{pH}$-value of aqueous phase is plotted in Figure 2 for both extractants and the three considered solvents without 1-octanol. Although the variations of extraction efficiency are rather similar regardless of the extractant type, the phenomena controlling them are different.

Therefore, for the reactive extraction with TOA, from Figure 2 it can be seen that the efficiency of pantothenic acid separation initially increases slowly with the increase in $\mathrm{pH}$-value of aqueous solution, reaching a maximum level corresponding to $\mathrm{pH}=2$, then decreases. Generally, the yields of reactive extraction of carboxylic acids with an extractant of high molecular weight amine type are continuously reduced by increasing the $\mathrm{pH}$-value, due to the carboxylic group or groups' dissociation, which become unable to react with the extractant. ${ }^{17}$ The same phenomenon also controls the extraction of pantothenic acid with TOA. Because the acid index of pantothenic acid is 4.41 at $25{ }^{\circ} \mathrm{C},{ }^{4}$ its ionization at $-\mathrm{COOH}$ group is more important at $\mathrm{pH}$-values over 3 and, consequently, the extraction is efficient in the strong acidic $\mathrm{pH}$-domain. However, the chemical stability of pantothenic acid is significantly affected in the pH-domain below 3 and above $7 .{ }^{20}$ Consequently, regardless of the experimented solvent, and considering the initial solute concentration of $5 \mathrm{~g} \mathrm{~L}^{-1}$, the extraction yield of pantothenic acid reached at $\mathrm{pH}=1$ is inferior to that corresponding to $\mathrm{pH}=2$ of aqueous solution, due both to the extractant protonation and the acid chemical degradation.

Due to the superior ability of solvents with higher polarity to solubilize the dissociated molecules, the maximum extraction degree of pantothenic acid with TOA was recorded for dichloromethane (Figure 2). At $\mathrm{pH}=2$ the reactive extraction yield for this solvent was 1.09 times higher than that for butyl acetate, and 1.4 times higher than that corresponding to $n$-heptane.

The reactive extraction with D2EHPA occurs if the amide group of pantothenic acid exists in protonated form at the carbonyl oxygen, respectively, in the highly acidic domain. On the other hand, the strong acidic domain induces also the protonation of extractant, a phenomenon which hinders its reac- 

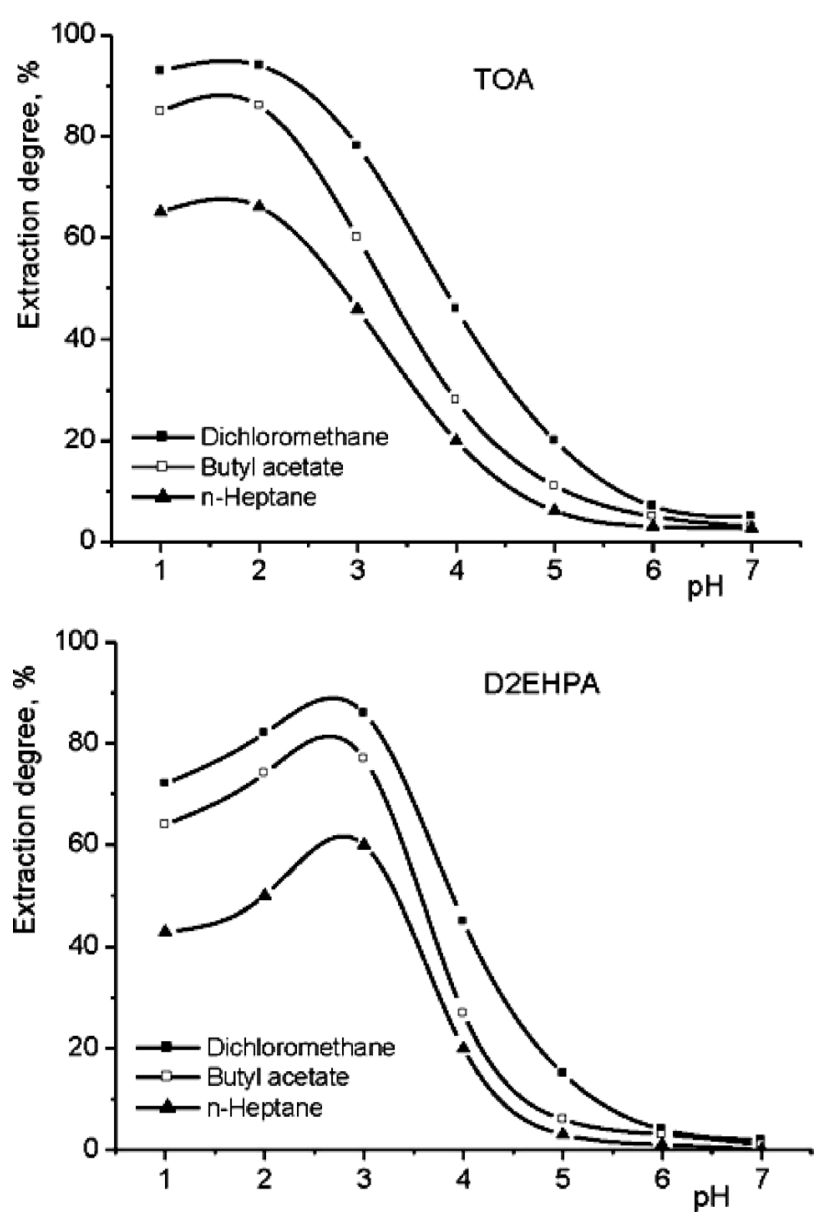

Fig. 2 - Influence of pH-value of aqueous phase on efficiency of reactive extraction of pantothenic acid with TOA and D2EHPA without 1-octanol (extractants concentration = $\left.40 \mathrm{~g} \mathrm{~L}^{-1}\right)$

tion with pantothenic acid. ${ }^{18}$ In this case, due to these two contrary phenomena induced at low $\mathrm{pH}$-value, the maximum extraction efficiency with D2EHPA is reached for $\mathrm{pH}=3$ (Figure 2). The further increase in $\mathrm{pH}$-value affects the protonation of carbonyl group and induces the dissociation of carboxylic group, both effects exhibiting a negative influence on extraction efficiency.

Compared to the extraction with TOA, the maximum level of extraction degree with D2EHPA is more obvious, because in the strong acidic domain, the protonation of organophosphoric extractant is cumulated with the chemical degradation of solute. The difference between extraction yields related to the three solvents is maintained also in the case of reactive extraction with D2EHPA. For the optimum $\mathrm{pH}$-value, the extraction efficiency recorded for dichloromethane was greater by 1.12 times than that for butyl acetate, and by 1.42 times than that for $n$-heptane.

By comparing the extraction yields reached for both extractants, it can be observed that TOA is more efficient. Thus, at the specific optimum
$\mathrm{pH}$-values, namely $\mathrm{pH}=2$ for TOA and $\mathrm{pH}=3$ for D2EHPA, respectively, the increase of solvent polarity leads to the variation of yields difference of 6 to $9 \%$ in favour of TOA. These differences increase significantly for the more acidic $\mathrm{pH}$-value, becoming $21-22 \%$ at $\mathrm{pH}=1$, but are attenuated and become insignificant at $\mathrm{pH}$ above 3 .

For elucidating the mechanism of pantothenic acid extraction, for both extractants it was assumed that $\mathrm{n}$ molecules of extractant, $\mathrm{E}$, and one solute molecule participate in the formation of the interfacial compound, as mentioned previously. In these circumstances, the reactive extraction of pantothenic acid with TOA can be described by the following interfacial equilibrium:

$$
\mathrm{HA}_{(\mathrm{aq})}+\mathrm{nE}_{(\text {org) }} \rightleftarrows \mathrm{HAE}_{\mathrm{n}(\mathrm{org})}
$$

(HA symbolizes the pantothenic acid).

Therefore, the distribution coefficient, $D$, can be calculated by the expression:

$$
D=\frac{\left[H A E_{n(\text { org })}\right]}{\left[\overline{H A_{(a q)}}\right]}
$$

where $\left[\overline{H A_{(a q)}}\right]$ is the acid overall concentration in the aqueous phase, while $\left[H A E_{n(o r g)}\right]$ represents the overall concentration of extracted compound in the solvent phase, both at the equilibrium state. According to the interfacial equilibrium, the extraction constant, $K_{\mathrm{E}}$, can be calculated with the following relationship:

$$
K_{E}=\frac{\left[H A E_{n(\text { org })}\right]}{\left[H A_{(a q)}\right] \cdot\left[E_{(\text {org })}\right]^{n}}
$$

Thus, the concentration of extracted compound is:

$$
\left[H A E_{n(\text { org })}\right]=K_{E} \cdot\left[H A_{(a q)}\right] \cdot\left[E_{(\text {org })}\right]^{n}
$$

The study on the interfacial mechanism of reactive extraction with TOA was carried out at the optimum $\mathrm{pH}$-value of 2 . Thus, the concentration of pantothenic acid molecules with undissociated $\mathrm{COOH}$ group from aqueous phase, $\left[H A_{(a q)}\right]$, is calculated by means of the acid overall concentration in aqueous phase and the concentration of dissociated acid, $\left[A^{-}(a q)\right]$ :

$$
\left[H A_{(a q)}\right]=\left[\overline{H A_{(a q)}}\right]-\left[A^{-}(a q)\right]
$$

The dissociation constant, $K_{\mathrm{a}}$ is defined according to the following equilibrium: 


$$
\begin{aligned}
\mathrm{HA}_{(\mathrm{aq})} & \rightleftarrows \mathrm{A}_{(\mathrm{aq})}^{-}+\mathrm{H}^{+}(\mathrm{aq}) \\
K_{a} & =\frac{\left[A^{-}{ }_{(a q)}\right] \cdot\left[H^{+}\right]}{\left[H A_{(a q)}\right]}
\end{aligned}
$$

Based on the equations (4) and (5), the expression for concentration of undissociated pantothenic acid from the aqueous phase becomes:

$$
\left[H A_{(a q)}\right]=\frac{\left[\overline{H A_{(a q)}}\right]}{1+\frac{K_{a}}{\left[H^{+}\right]}}
$$

By combining the equations (1), (3) and (6), the following relationship for the distribution coefficient is obtained:

$$
D=\frac{K_{E} \cdot\left[E_{(\text {org })}\right]^{n}}{1+\frac{K_{a}}{\left[H^{+}\right]}}
$$

The correlation (7) represents in logarithmic form the equation of a straight line:

$$
\ln D+\ln \left(1+\frac{K_{a}}{\left[H^{+}\right]}\right)=\ln K_{E}+n \cdot \ln \left[E_{(\text {org })}\right]
$$

Because the initial concentration of TOA is higher than the initial concentration of pantothenic acid, $\left[E_{(o r g)}\right]$ could be assumed to be the initial concentration of extractant in the solvent phase. By means of the above algorithm, from the slope of the straight line given by equation (8), it is possible to determine the number of aminic extractant molecules participating in the interfacial reaction with the solute, while the value of extraction constant could be calculated from the straight line intercept.

In order to establish the number of aminic extractant molecules reacting with pantothenic acid, as well as the influence of solvent polarity on the interfacial compound structure, the influence of TOA concentration on extraction efficiency was studied for all three solvents without 1-octanol, the experimental variations being indicated in Figure 3.

The data from Figure 3 were used for plotting in Figure 4 the straight lines described by equation (8), for each solvent.

Table 1 indicates that the values of the straight lines slopes depend on the solvent type, suggesting the modification of chemical structure of the interfacial compound in relation with the polarity of organic phase. Therefore, the reactive extraction of pantothenic acid with TOA in low-polar solvent, namely $n$-heptane, occurs with the formation of an

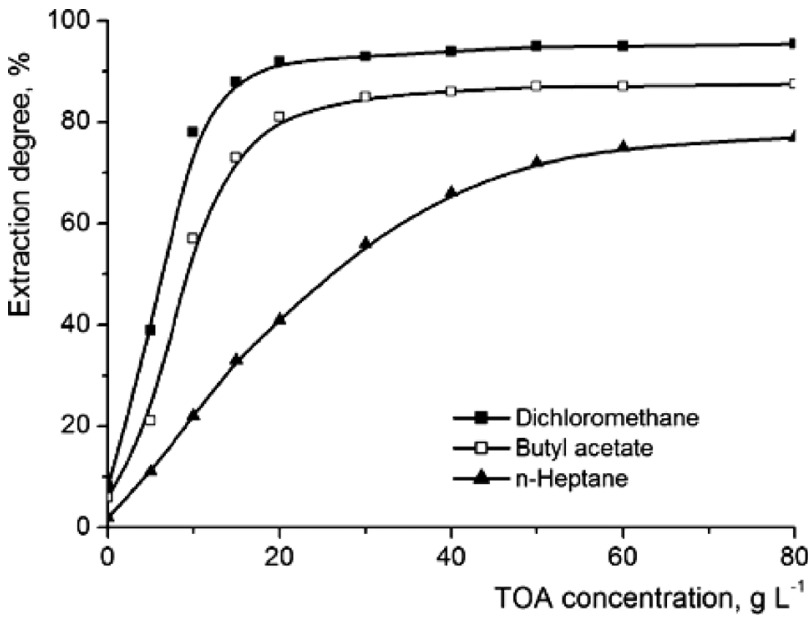

Fig. 3 - Influence of TOA concentration on reactive extraction efficiency of pantothenic acid without 1-octanol $(\mathrm{pH}=2)$

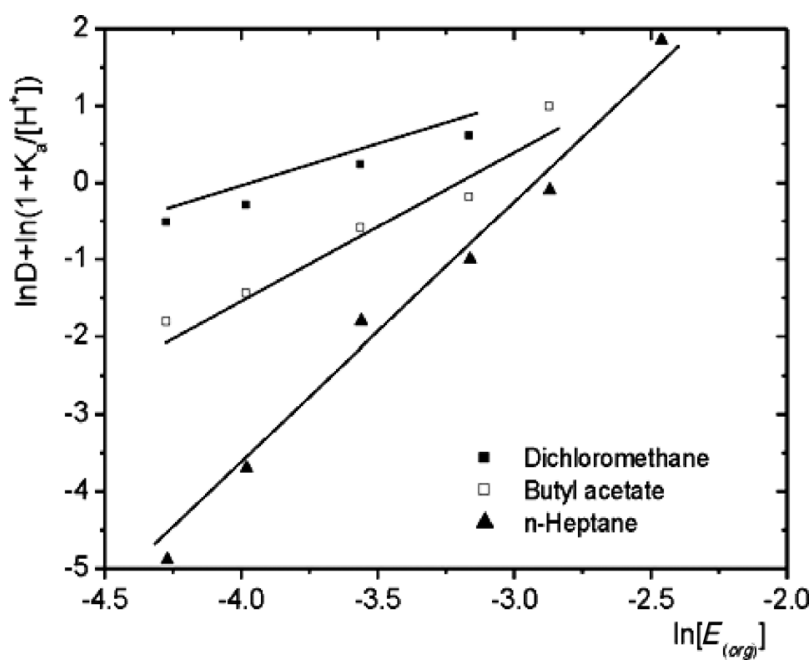

Fig. 4 - Graphical representation of the straight lines given by equation (8) for solvents without 1-octanol $(\mathrm{pH}=2)$

interfacial aminic adduct with four extractant molecules.

These results are supported by the variation of extraction yield plotted in Figure 3, and confirm the reports from literature regarding the formation of

Table 1 -Number of extractant molecules included in the interfacial compound structure, $n$, for solvents without 1-octanol

\begin{tabular}{l|l|c}
\hline Extractant & \multicolumn{1}{|c|}{ Solvent } & $\begin{array}{c}\text { Number of extractant molecules } \\
(\mathrm{n})\end{array}$ \\
\hline \multirow{3}{*}{ TOA } & $n$-Heptane & 3.92 \\
& Butyl acetate & 2.04 \\
& Dichloromethane & 0.93 \\
\hline \multirow{3}{*}{ D2EHPA } & $n$-Heptane & Butyl acetate \\
& Dichloromethane & 2.11 \\
& & 1.91 \\
\hline
\end{tabular}


aminic associations in low-polar solvents. ${ }^{17}$ Thus, it can be observed that, for $n$-heptane, the extraction efficiency increases significantly by increasing the extractant concentration up to $40 \mathrm{~g} \mathrm{~L}^{-1}(0.11 \mathrm{M})$, a limit which indicates the molar ratio between pantothenic acid and extractant of 1:4. For butyl acetate, the extraction yield is strongly enhanced by increasing the TOA concentration up to $15-20 \mathrm{~g} \mathrm{~L}^{-1}(0.05 \mathrm{M})$, a value related to the molar ratio solute:extractant of $1: 2$, the increase becoming slower for higher concentrations of amine. The least extended domain of extractant concentration corresponding to the important influence of this parameter on extraction was recorded for dichloromethane. In this case, only the extractant concentration increase up to $10 \mathrm{~g} \mathrm{~L}^{-1}(0.028 \mathrm{M})$ influences strongly the extraction yield, a result suggesting that each reactant participates with one molecule at the interfacial compound formation.

It can be concluded that the decrease in solvent polarity from dichloromethane to $n$-heptane facilitates the formation of aminic adducts by hydrogen-bonding interactions, and increases the number of extractant molecules included in these adducts from 1 to 4.

The experiments concerning the investigation of reactive extraction mechanism of pantothenic acid with D2EHPA were also carried out at the optimum $\mathrm{pH}$-value of aqueous phase, $\mathrm{pH}=3$. In this case, the aminic group is the active one, the efficiency of extraction being controlled by its ability to be protonated and, implicitly, to react with the extractant. The interfacial reaction can be described by the following equilibrium:

$$
\mathrm{H}_{2} \mathrm{~A}_{(\mathrm{aq})}^{+}+\mathrm{nE}_{(\text {org })} \rightleftarrows \mathrm{HAE}_{\mathrm{n}(\mathrm{org})}+\mathrm{H}^{+} \text {(aq) }
$$

According to this interfacial equilibrium, the distribution coefficient, $D$, is:

$$
D=\frac{\left[H A E_{n(o)}\right]}{\left[H_{2} A^{+}(a q)\right]}
$$

where $\left[\mathrm{H}_{2} \mathrm{~A}^{+}{ }_{(a q)}\right]$ and $\left[H A E_{n(o)}\right]$ represent the overall concentrations of the considered components at the equilibrium state.

The extraction constant, $K_{\mathrm{E}}$, can be calculated with the following relationship:

$$
\begin{aligned}
K_{E}= & \frac{\left[H A E_{n(o)}\right] \cdot\left[H_{(a q)}^{+}\right]}{\left[H_{2} A_{(a q)}^{+}\right] \cdot\left[E_{(o)}\right]^{n}}=\frac{\left[H A E_{n(o)}\right]^{2}}{\left[H_{2} A_{(a q)}^{+}\right] \cdot\left[E_{(o)}\right]^{n}} \\
& \Rightarrow\left[H A E_{n(o)}\right]^{2}=K_{E} \cdot\left[H_{2} A_{(a q)}^{+}\right] \cdot\left[E_{(o)}\right]^{n}
\end{aligned}
$$

The ionization constant of amidic group at $25{ }^{\circ} \mathrm{C}$ is $K_{\mathrm{b}}=2.04 \cdot 10^{-10,4}$ and corresponds to the following equilibrium established in aqueous phase:

$$
\begin{gathered}
\mathrm{HA}+\mathrm{H}_{2} \mathrm{O} \rightleftarrows \mathrm{H}_{2} \mathrm{~A}^{+}+\mathrm{HO}^{-} \\
K_{b}=\frac{\left[H_{2} A_{(a q)}^{+}\right] \cdot\left[H O^{-}\right]}{\left[H A_{(a q)}\right]}=\frac{10^{-14} \cdot\left[H_{2} A_{(a q)}^{+}\right]}{\left[H A_{(a q)}\right] \cdot\left[H_{(a q)}^{+}\right]}
\end{gathered}
$$

The concentration of protonated pantothenic acid in aqueous phase, $\left[\mathrm{H}_{2} A_{(a q)}^{+}\right]$, is calculated by means of its overall concentration in aqueous phase, $\left[\overline{H A_{(a q)}}\right]$, and concentration of its non-ionized molecules, $\left[H A_{(a q)}\right]$ :

$$
\begin{gathered}
{\left[H_{2} A_{(a q)}^{+}\right]=\left[\overline{H A_{(a q)}}\right]-\left[H A_{(a q)}\right]} \\
{\left[H A_{(a q)}\right]=\frac{10^{-14} \cdot\left[H_{2} A_{(a q)}^{+}\right]}{K_{b} \cdot\left[H_{(a q)}^{+}\right]}} \\
\Rightarrow\left[H_{2} A_{(a q)}^{+}\right]=\frac{\left[\overline{H A_{(a q)}}\right]}{\left.1+\frac{10^{-14}}{K_{b} \cdot\left[H_{(a q)}^{+}\right.}\right]}
\end{gathered}
$$

Therefore, the expression for distribution coefficient becomes:

$$
\begin{gathered}
D^{2}=\frac{\left[H A E_{n(o)}\right]^{2}}{\left[H_{2} A_{(a q)}^{+}\right]^{2}}=\frac{K_{E} \cdot\left[E_{(o)}\right]^{n}}{\left[H_{2} A_{(a q)}^{+}\right]}= \\
=\frac{K_{E} \cdot\left[E_{(o)}\right]^{n} \cdot\left(1+\frac{10^{-14}}{K_{b} \cdot\left[H_{(a q)}^{+}\right]}\right)}{\left[\overline{H A_{(a q)}}\right]}
\end{gathered}
$$

The logarithmic form of equation (16) gives a straight-line expression:

$$
2 \ln D-\ln \frac{1+\frac{10^{-14}}{K_{b} \cdot\left[H_{(a q)}^{+}\right]}}{\left[\overline{H A_{(a q)}}\right]}=\ln K_{E}+n \cdot \ln \left[E_{(o)}\right]
$$

which is used for the graphical determination of $n$ and $K_{\mathrm{E}}$, similar to the algorithm presented for reactive extraction with TOA ( $\left[E_{(.0)}\right]$ could also be assumed to be equal to the initial concentration of D2EHPA in the organic solvent).

The dependence between the extraction efficiency and D2EHPA concentration is plotted in Figure 5 for all studied solvents without 1-octanol added, while the straight lines correspond to equation (17) in Figure 6. 


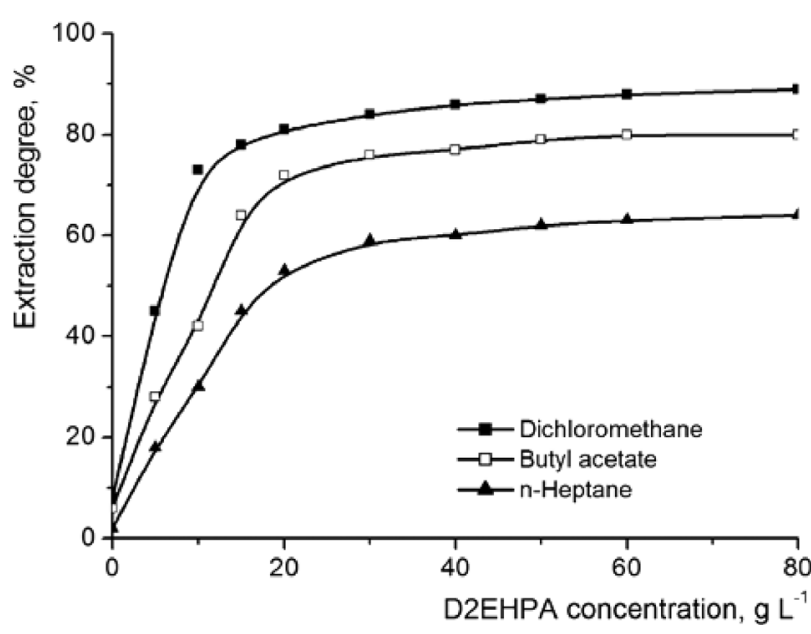

Fig. 5 - Influence of D2EHPA concentration on reactive extraction efficiency of pantothenic acid without 1-octanol $(p H=3)$

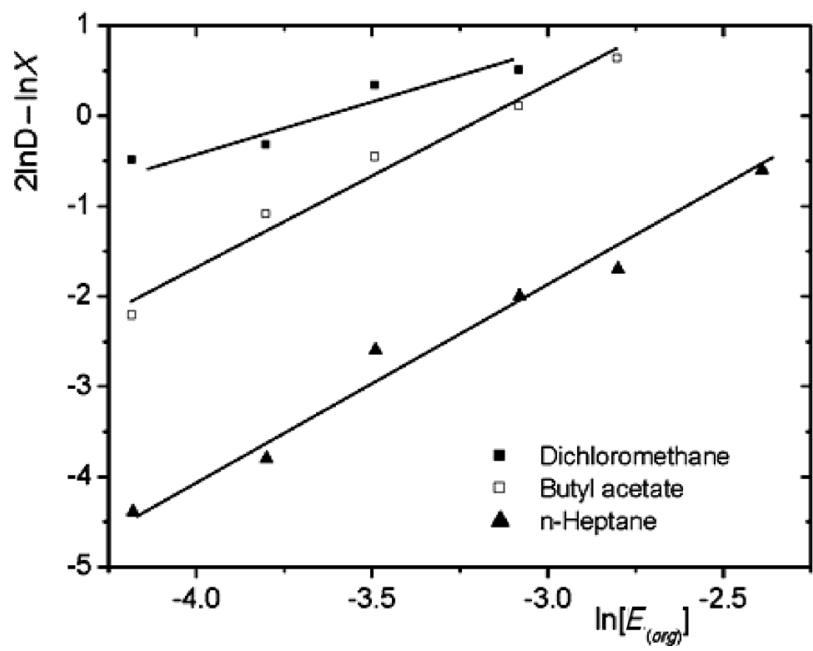

Fig. 6-Graphical representation of the straight lines given by equation (17) for solvents without 1-octanol $\left(p H=3 ; \quad X=\left(1+10^{-14} / K_{b} \cdot\left[H_{(a q)}^{+}\right]\right) /\left[H_{(a q)}\right]\right)$

Compared to the extraction of pantothenic acid with TOA dissolved in $n$-heptane, from Figure 6 it can be observed that only a maximum of two molecules of D2EHPA and one of solute react at the interface between aqueous phase and this solvent. The reduction in the extractant number participating in extracted compound formation compared to the case of TOA could be attributed to the supplementary steric hindrance induced by the intermediary position of amide group in the molecular structure of pantothenic acid.

For the reactive extraction in butyl acetate and dichloromethane, the interfacial product includes the same number of D2EHPA molecules as those of TOA in the above discussed extraction systems. As it can be seen from Figure 5, the limits of D2EHPA concentration increase correlated with the significant influence on pantothenic acid extraction yield are $15 \mathrm{~g} \mathrm{~L}^{-1}(0.046 \mathrm{M})$ for the solvents with lower dielectric constants ( $n$-heptane and butyl acetate), and up to $10 \mathrm{~g} \mathrm{~L}^{-1}(0.03 \mathrm{M})$ for dichloromethane. These values correspond with the calculated ratios between the number of solute and extractant molecules from the proposed structure of interfacial compound: both for $n$-heptane and butyl acetate it is 1:2, and 1:1 for dichloromethane (Table 1).

As presented above, the solvent polarity represents an important parameter that controls the extraction of ionizable solutes. The dielectric constant is considered a characteristic of solvent-solute local interactions, inducing the limitation of solute solvation by solvent or extractant, due to the presence of ionizable groups in the molecular structure of solute. The modification of dielectric constant has a smaller effect on the solubility and extraction of nonelectrolytes or weak electrolytes, but it becomes an important factor for the extraction of dissociable solutes, as acids. ${ }^{17}$ Therefore, the solvent polarity and the formation of interfacial adducts have a strong influence on the extraction constant, mainly through the extraction mechanism and efficiency. The extraction constant for both extractants were calculated taking into consideration the data presented in Figures 4 and 6 (Table 2).

Table 2 -Expressions and values of extraction constants for the studied extraction systems without 1-octanol

\begin{tabular}{c|c|c|c}
\hline Extractant & Solvent & Extraction constant & Value \\
\hline$n$-Heptane & $K_{E}=\frac{\left[H A E_{4(\text { org })}\right]}{\left[H A_{(a q)}\right] \cdot\left[E_{(\text {org })}\right]^{4}}$ & $\begin{array}{c}2.22 \cdot 10^{5} \\
\left(\mathrm{~L}^{4} \mathrm{~mol}^{-4}\right)\end{array}$ \\
TOA & $\begin{array}{l}\text { Butyl } \\
\text { acetate }\end{array}$ & $K_{E}=\frac{\left[H A E_{2(\text { org })}\right]}{\left[H A_{(a q)}\right] \cdot\left[E_{(\text {org })}\right]^{2}}$ & $\begin{array}{c}7.50 \cdot 10^{2} \\
\left(\mathrm{~L}^{2} \mathrm{~mol}^{-2}\right)\end{array}$ \\
& $\begin{array}{l}\text { Dichloro- } \\
\text { methane }\end{array}$ & $K_{E}=\frac{\left[H A E_{(\text {org })}\right]}{\left[H A_{(a q)}\right] \cdot\left[E_{(\text {org })}\right]}$ & $\begin{array}{c}4.30 \cdot 10^{2} \\
\left(\mathrm{~L} \mathrm{~mol}^{-1}\right)\end{array}$
\end{tabular}

$n$-Heptane $\quad K_{E}=\frac{\left[\mathrm{HAE}_{2(\text { org }}\right] \cdot\left[\mathrm{H}_{(\text {aq) }}^{+}\right]}{\left[\mathrm{H}_{2} A_{(\text {aq }}^{+}\right] \cdot\left[E_{(\text {org }}\right]^{2}} \quad\left(\begin{array}{l}58.26 \\ \left(\mathrm{~L} \mathrm{~mol}^{-1}\right)\end{array}\right.$

D2EHPA $\begin{array}{ll}\begin{array}{c}\text { Butyl } \\ \text { acetate }\end{array} \quad K_{E}=\frac{\left[\mathrm{HAE}_{2(\text { org })}\right] \cdot\left[H_{(a q)}^{+}\right]}{\left[H_{2} A_{(a q)}^{+}\right] \cdot\left[E_{(\text {org })}\right]^{2}} & 4.93 \cdot 10^{2} \\ (\mathrm{~L} \mathrm{~mol})^{-1}\end{array}$

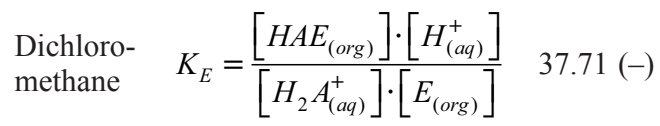


According to the results given in Table 2, for the reactive extraction of pantothenic acid with TOA in the absence of 1-octanol, the formation of aminic adducts leads to the increase in extraction constant by more than 500 times from dichloromethane to $n$-heptane, a variation which indicates a significant shift to the right side of the interfacial equilibrium. However, if the mechanism of the interfacial reaction remains the same for different solvents, as in the case for extraction with D2EHPA in $n$-heptane and butyl acetate, the organic phase polarity exhibits directly a favourable effect on the extraction equilibrium. Thus, by varying the dielectric constant from $n$-heptane to butyl acetate, the value of extraction constant increased 8.5 times, while that reached for dichloromethane is the lowest one (37.71).

\section{Reactive extraction in the presence of 1 -octanol}

In order to improve the efficiency of extraction, a second solvent immiscible with the aqueous phase can be added into the organic phase, its addition increasing the organic phase polarity and, implicitly, facilitating the solubilization of polar molecules. This second solvent is called "phase modifier", usually being an alcohol with more than 6 carbon atoms. ${ }^{17}$ For this purpose, 1 -octanol was used in the experiments.

Regardless of the used solvent or extractant, from Figure 7 it can be observed that, the addition of 1-octanol into the organic phase does not change the shapes of the dependences between the reactive extraction efficiency and $\mathrm{pH}$ of the aqueous phase. The presence of 1-octanol improves the extraction degree, an effect that is more pronounced for the solvents with lower polarity.

At the optimum $\mathrm{pH}$-values corresponding to the reactive extraction with TOA and D2EHPA, the yield of extraction in the presence of 1-octanol increases $1-15 \%$ if TOA is used, and $3-12 \%$ for D2EHPA compared to the absence of this alcohol. These differences are amplified at higher $\mathrm{pH}$-values of aqueous solution. Moreover, the increase in the solvent's ability to solubilize polar or dissociated molecules of pantothenic acid in the presence of 1-octanol diminishes the difference between the values of extraction yield reached for a certain extractant. Consequently, the extraction degrees for all the three solvents become closer.

For underlining the positive influence of 1-octanol on reactive extraction efficiency, the amplification factor was introduced, defined as the ratio between the pantothenic acid extraction degrees for the solvent with and, respectively, without 1-octanol. The dependences of amplification factor on the
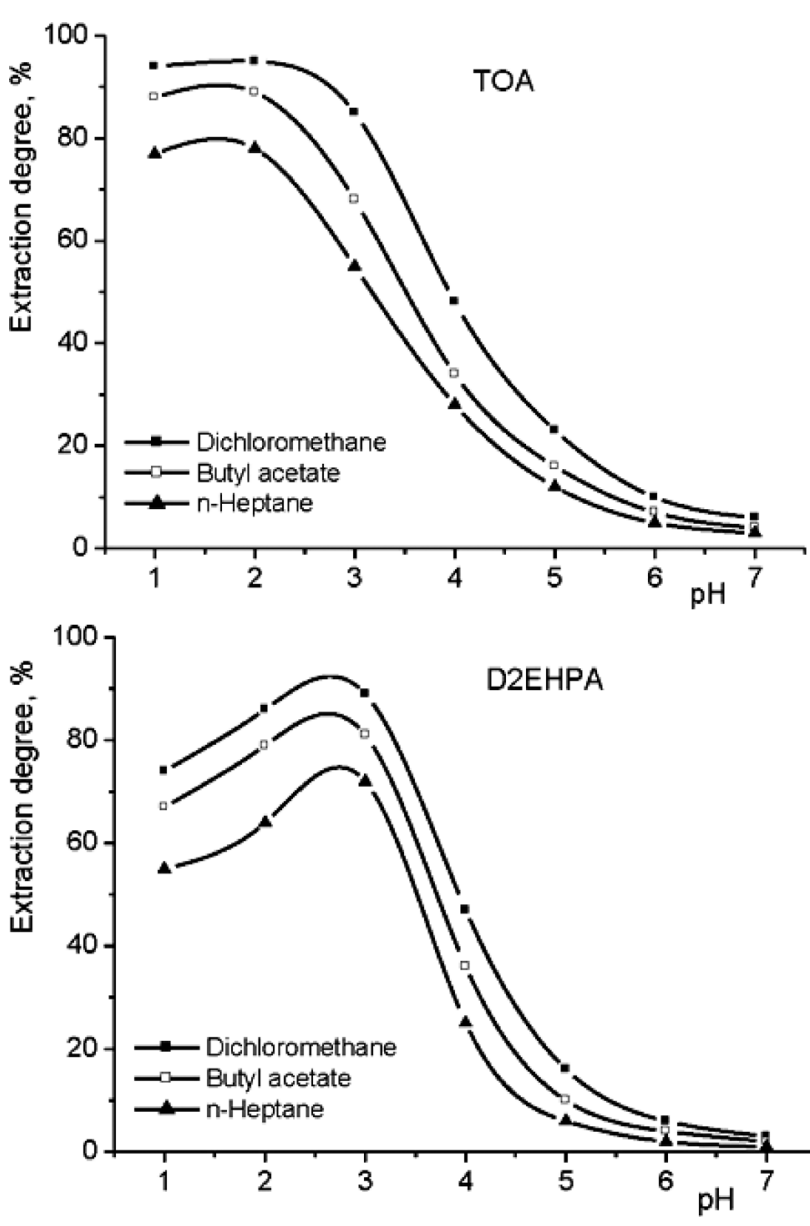

Fig. 7 - Influence of pH-value of aqueous phase on efficiency of reactive extraction of pantothenic acid with TOA and D2EHPA with 1-octanol added (extractants concentration $=40 \mathrm{~g} \mathrm{~L}^{-1}$ )

pH-value of aqueous phase for the studied extraction systems are plotted in Figure 8.

These variations confirm that the effect of 1-octanol addition is more important for low-polar solvents. Thus, compared to the extraction without 1-octanol, for a volumetric fraction of alcohol of 0.20 , the maximum increase in extraction degree of pantothenic acid with TOA was 1.3 times for dichloromethane, 1.4 times for butyl acetate, and 1.7 times for $n$-heptane. Similarly, the efficiency of reactive extraction with D2EHPA increased up to 1.6 times for dichloromethane, 2 times for butyl acetate, and 2.4 times for $n$-heptane.

However, depending on the solvent type, the differentiation of the shapes describing the correlations between the amplification factors and $\mathrm{pH}$ can be observed in Figure 9.

In the case of reactive extraction with TOA, regardless of the solvent polarity, the increase in $\mathrm{pH}$-value up to 4 exhibits an insignificant influence on the amplification factor, because this $\mathrm{pH}$-domain corresponds to the highest efficiency of reactive extraction. The further increase in $\mathrm{pH}$ leads to a significant increase in amplification factor, which 

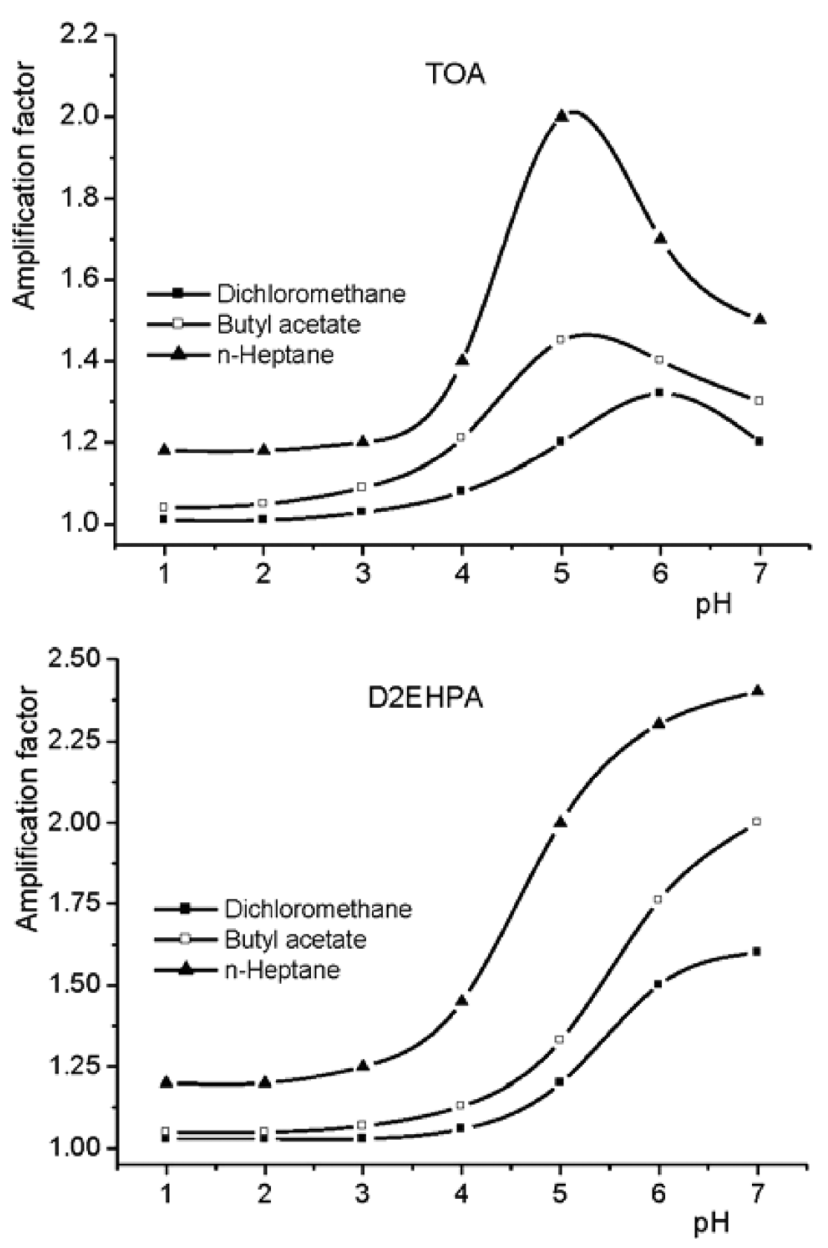

Fig. 8 - Influence of pH-value of aqueous phase on amplification factor for reactive extraction of pantothenic acid with TOA and D2EHPA (extractants concentration $=40 \mathrm{~g} \mathrm{~L}^{-1}$ )

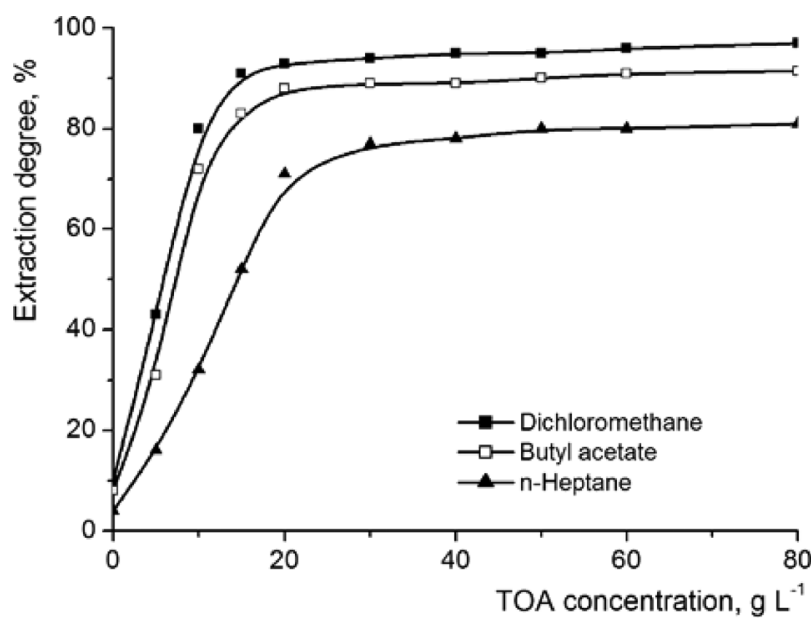

Fig. 9 - Influence of TOA concentration on reactive extraction efficiency of pantothenic acid with 1-octanol added $(\mathrm{pH}=2)$

reaches a maximum value, followed by its decrease for $\mathrm{pH}$ above 5-6. This variation is the consequence of additional solubilization of ionized pantothenic acid molecules in the presence of 1 -octanol at $\mathrm{pH}$-values higher than the optimum value. The pro- nounced dissociation of carboxyl group at neutral or alkaline $\mathrm{pH}$ domain reduces the solubility also in polar solvents, and leads to the decrease in the amplification factor for $\mathrm{pH}>5$. This variation of amplification factor becomes more obvious with the decrease in solvent dielectric constant.

For reactive extraction with the organophosphoric extractant, the variation of amplification factor is different. This parameter increases slowly up to the $\mathrm{pH}$-value corresponding to the maximum of extraction efficiency $(\mathrm{pH}=3)$, then increases continuously and strongly for higher $\mathrm{pH}$-values of aqueous phase. Because - $\mathrm{COOH}$ group does not react with D2EHPA, its dissociation at higher $\mathrm{pH}$-values facilitates the continuous increase in the magnitude of positive influence of 1-octanol, this phenomenon leading to the enhancement of the amplification factor. As in the previous case, the variation of the amplification factor is more important for low-polar solvents, namely $n$-heptane.

For establishing the interfacial reaction mechanisms and identifying the possible changes in the structure of the interfacial compounds due to the addition of 1-octanol in the organic phase, the straight lines described by equations (8) and (17) were plotted and analysed for the three solvents containing $20 \%$ vol. alcohol. For this purpose, the graphical correlations between the extraction yield and extractant concentration were firstly analysed for each extraction system containing $20 \%$ vol. 1-octanol.

In the case of reactive extraction with the aminic extractant, the calculations are based on Figures 9 and 10. Therefore, for solvents with lower dielectric constants, namely $n$-heptane and butyl acetate, the number of TOA molecules participating in the interfacial reaction with pantothenic acid is halved by

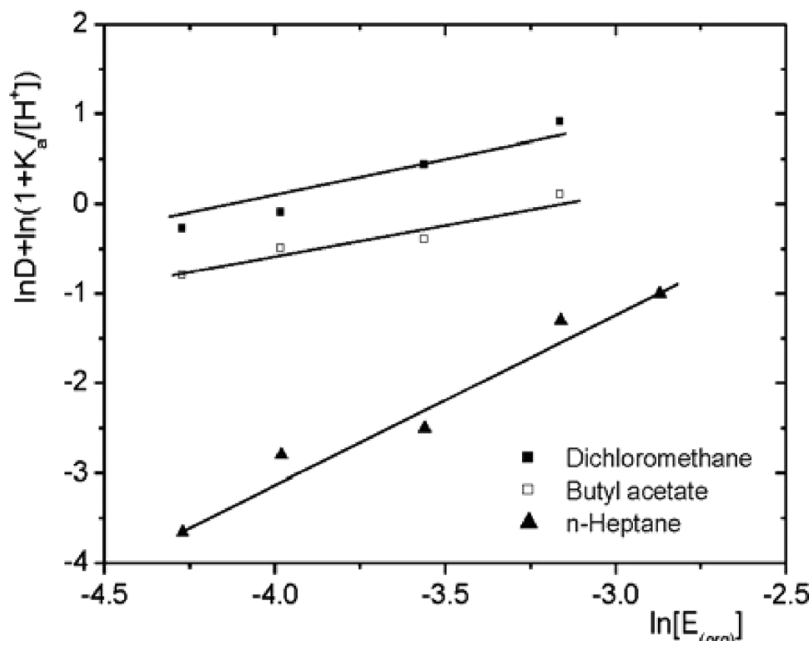

Fig. 10 - Graphical representation of the straight lines given by equation (8) for solvents with 1-octanol added $(\mathrm{pH}=2)$ 
Table 3 -Number of extractant molecules included in the interfacial compound structure, $n$, for solvents with 1-octanol

\begin{tabular}{l|l|c}
\hline Extractant & \multicolumn{1}{|c|}{ Solvent } & $\begin{array}{c}\text { Number of extractant molecules } \\
(\mathrm{n})\end{array}$ \\
\hline \multirow{3}{*}{ TOA } & n-Heptane & 2.11 \\
& Butyl acetate & 1.08 \\
& Dichloromethane & 1.07 \\
\hline \multirow{3}{*}{ D2EHPA } & n-Heptane & 0.91 \\
& Butyl acetate & 1.05 \\
& Dichloromethane & 0.93 \\
\hline
\end{tabular}

adding 1-octanol into the organic phase (Table 3). This result underlines the role of organic phase low polarity in promoting the formation of aminic adducts by solvating the solute, the increase in solvent polarity hindering this process. The addition of 1-octanol in dichloromethane, which possesses the highest dielectric constant among the experimented solvents, does not influence the extraction mechanism of pantothenic acid with TOA, the structure of the extracted compound remaining the same to that corresponding to the extraction without 1-octanol.

The stoichiometry of the interfacial reaction between pantothenic acid and TOA is also suggested by Figure 9, which indicates that the reactive extraction efficiency is significantly improved only by increasing TOA concentration up to $10 \mathrm{~g} \mathrm{~L}^{-1}$ $(0.028 \mathrm{M})$ for dichloromethane and butyl acetate, and up to $15-20 \mathrm{~g} \mathrm{~L}^{-1}(0.05 \mathrm{M})$ for $n$-heptane. These limits of extractant concentration can be attributed to the molar ratios between solute and TOA of $1: 1$ for the two solvents with higher dielectric constant, respectively of 1:2 for $n$-heptane.

A similar effect of reducing the number of extractant molecules included in the extracted compound structure was observed also for extraction with D2EHPA (Figures 11 and 12). Therefore, regardless of the solvent used, each component of the extraction system participates with one molecule in the interfacial reaction, the hydrophobic compound formed being of ammonium salt type (Table 3 ). According to Figure 11, this conclusion is supported by the significant increase in reactive extraction yield by increasing D2EHPA concentration in organic phase only up to $10 \mathrm{~g} \mathrm{~L}^{-1}(0.03 \mathrm{M})$ for all considered solvents.

Being directly related to the mechanism of reactive extraction, the extraction constant values for the two extractants and three solvents were modified by adding 1-octanol in the organic phase (Table $4)$.

As in the case of extraction without 1-octanol, for the reactive extraction with TOA, the values of

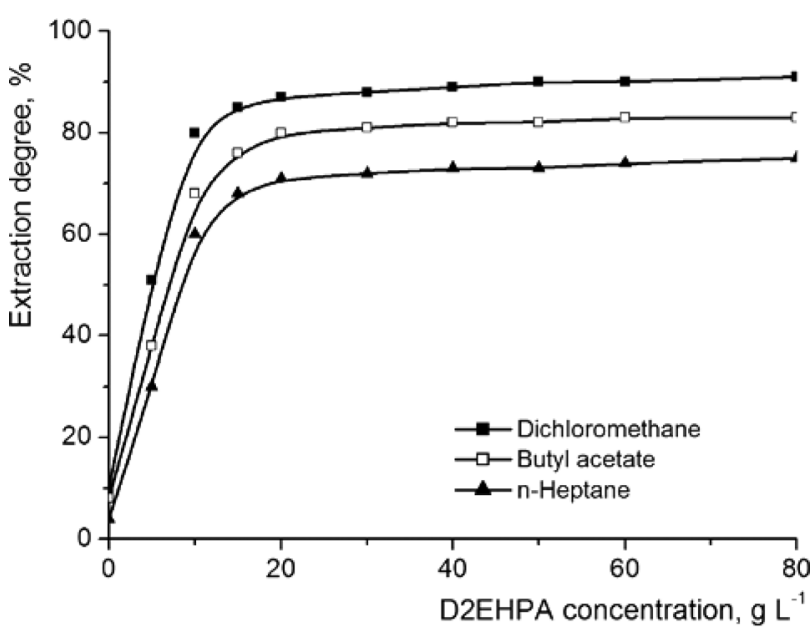

Fig. 11 - Influence of D2EHPA concentration on reactive extraction efficiency of pantothenic acid with 1-octanol added $(\mathrm{pH}=3)$

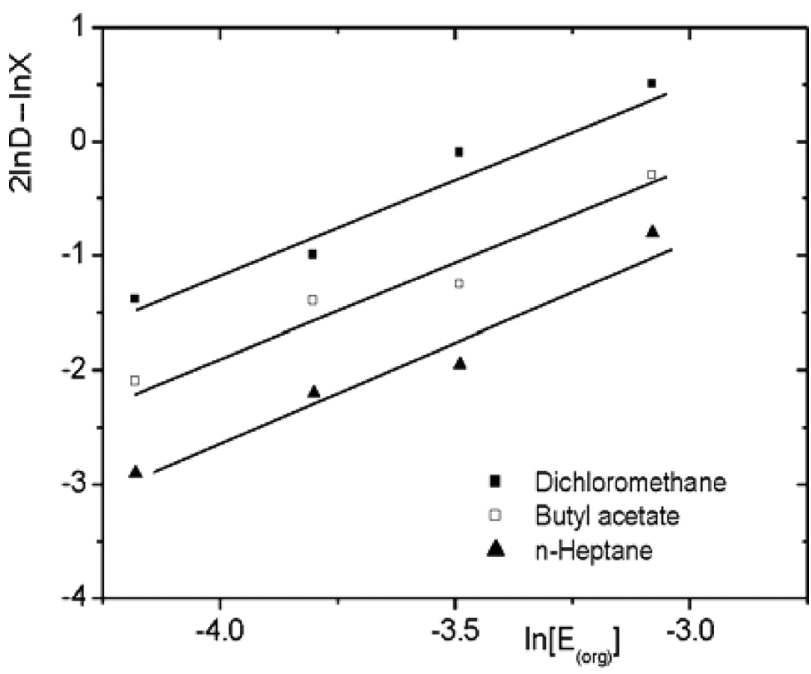

Fig. 12 - Graphical representation of the straight lines given by equation (17) for solvents without 1-octanol $\left(p H=3 ; \quad X=\left(1+10^{-14} / K_{b} \cdot\left[H_{(a q)}^{+}\right]\right) /\left[\overline{H A_{(a q)}}\right]\right)$

$K_{\mathrm{E}}$ suggest the importance of interfacial compound solvation by the extractant molecules in moving the interfacial equilibrium towards the formation of hydrophobic pantothenic acid-aminic extractant adducts. Therefore, compared to the extraction systems without 1-octanol, the reduction in the number of extractant molecules included in the structure of the interfacial complex in the presence of 1-octanol determines the significant decrease in the extraction constant values for butyl acetate and $n$-heptane. Moreover, the highest values of $K_{\mathrm{E}}$ obtained for extraction systems with alcohol corresponds to the formation of the interfacial adduct containing two aminic molecules, namely for extraction in $n$-heptane. If the interfacial reaction mechanism is similar in the presence of 1-octanol, as in the case of extraction in butyl acetate and dichloromethane, the superior polarity of organic phase exhibits a favourable effect on the extraction constant. 
Table 4-Expressions and values of extraction constants for the studied extraction systems with 1-octanol

\begin{tabular}{|c|c|c|c|}
\hline Extractant & Solvent & Extraction constant & Value \\
\hline \multirow{3}{*}{ TOA } & n-Heptane & $K_{E}=\frac{\left[H A E_{2}\right.}{\left[H A_{(a q)}\right] \cdot \mid}$ & $\begin{array}{c}1.16 \cdot 10^{2} \\
\left(\mathrm{~L}^{2} \mathrm{~mol}^{-2}\right)\end{array}$ \\
\hline & $\begin{array}{l}\text { Butyl } \\
\text { acetate }\end{array}$ & $\frac{\left[H A E_{(\text {org })}\right]}{\left.H A_{(a q)}\right] \cdot\left[E_{(\text {org })}\right.}$ & $\begin{array}{c}27.11 \\
\left(\mathrm{~L} \mathrm{~mol}^{-1}\right)\end{array}$ \\
\hline & $\begin{array}{l}\text { Dichloro- } \\
\text { methane }\end{array}$ & $\frac{\left[H A E_{(\text {org })}\right]}{\left.H A_{(a q)}\right] \cdot\left[E_{(\text {org })}\right.}$ & $\begin{array}{c}46.52 \\
\left(\mathrm{~L} \mathrm{~mol}^{-1}\right)\end{array}$ \\
\hline \multirow{3}{*}{ D2EHPA } & $n$-Heptane & $K_{E}=\frac{\left[H A E_{(o r g)}\right] \cdot\left[H_{(a q)}^{+}\right.}{\left[H_{2} A_{(a q)}^{+}\right] \cdot\left[E_{(o r g)}\right]}$ & $\begin{array}{l}4.11 \\
(-)\end{array}$ \\
\hline & $\begin{array}{l}\text { Butyl } \\
\text { acetate }\end{array}$ & $K_{E}=\frac{\left[H A E_{(o r g)}\right] \cdot\left[H_{(a q)}^{+}\right.}{\left[H_{2} A_{(a q)}^{+}\right] \cdot\left[E_{(o r g)}\right]}$ & $\begin{array}{c}8.58 \\
(-)\end{array}$ \\
\hline & $\begin{array}{l}\text { Dichloro- } \\
\text { methane }\end{array}$ & $K_{E}=\frac{\left[H A E_{(o r g)}\right] \cdot\left[H_{(a q)}^{+}\right.}{\left[H_{2} A_{(a q)}^{+}\right] \cdot\left[E_{(o r g)}\right]}$ & $\begin{array}{c}26.56 \\
(-)\end{array}$ \\
\hline
\end{tabular}

In the presence of 1-octanol, the mechanism of extraction with D2EHPA becomes the same for all solvents. Although the hindrance of extractants adducts formation reduces the extraction constants as compared to the systems without 1-octanol, the increase in dielectric constant from $n$-heptane to dichloromethane exhibits a positive effect on this parameter, and induces its increase by about 6.5 times.

\section{Conclusions}

The study on reactive extraction of pantothenic acid with TOA and D2EHPA dissolved in three solvents with different dielectric constants ( $n$-heptane, butyl acetate and dichloromethane), with and without 1-octanol added, has indicated that the mechanism of the interfacial reaction between the solute and the extractant is controlled by the extractant type and organic phase polarity. Regardless of the solvent used, the maximum efficiency for extraction with TOA is reached at $\mathrm{pH}=2$ related to the initial acid concentration, while for extraction with D2EH$\mathrm{PA}$ at $\mathrm{pH}=3$.

In the case of reactive extraction with TOA in the absence of 1-octanol, the reduction in the dielectric constant of the organic phase from dichloro- methane to $n$-heptane promotes the amine adducts formation and the modification of the interfacial equilibrium expression. For this reason, the structure of interfacial hydrophobic compound formed by pantothenic acid and aminic extractant was changed from $\mathrm{HAE}$ for dichloromethane to $\mathrm{HAE}_{2}$ for butyl acetate and $\mathrm{HAE}_{4}$ for $n$-heptane, respectively. When 1-octanol is added in the extraction system, due to an increase in organic phase polarity, the formation of aminic adducts is hindered, the structure of the interfacial complexes becoming HAE for dichloromethane and butyl acetate, and $\mathrm{HAE}_{2}$ for $n$-heptane.

A similar effect was observed for extraction with D2EHPA. Thus, in the absence of 1-octanol, the reactive extraction occurs by means of the interfacial formation of a hydrophobic compound with $\mathrm{HAE}_{2}$ structure for both $n$-heptane and butyl acetate, and with HAE general formula for dichloromethane. The addition of alcohol had modified only the mechanism of reactive extraction in $n$-heptane and butyl acetate, the structure of the extracted compound becoming HAE for all the three considered solvents.

Obviously, the value of extraction constant is influenced by extraction mechanism, implicitly by the solvent polarity and extractant type. For extraction with TOA, the highest values of extraction constant were obtained when aminic adducts had formed, at lower polarity of organic phase. Contrarily, for extraction with D2EHPA, when the extraction mechanism is the same for all solvents, the increase in organic phase polarity influenced positively the value of extraction constant.

\section{ACKNOWLEDGEMENTS}

This paper was published under the framework of the European Social Fund, Human Resources Development Operational Programme 2007-2013, project no. POSDRU/159/1.5/S/136893

This work was also supported by the Grant of the Romanian National Authority for Scientific Research, CNCS-UEFISCDI, project number PN-IIID-PCE-2011-3-0088

\section{References}

1. Sweetman, L., Pantothenic acid, in Coates, P. M., Blackman, M. R., Cragg, G. M., Levine, M., Moss, J. and White, J. D. (Eds.), Encyclopedia of Dietary Supplements, Marcel Dekker, New York, 2005, pp. 517-525.

2. Gonthier, A., Fayol, V., Viollet, J., Hartmann, D. J., Determination of pantothenic acid in foods: influence of the extraction method, Food Chem. 63 (1998) 287. doi: http://dx.doi.org/10.1016/S0308-8146(97)00136-2 
3. Kivrak, I., Chemical constituents: water-soluble vitamins free amino acids and sugar profile from Ganoderma adspersum, Nat. Prod. Res. 29 (2015) 518. doi: http://dx.doi.org/10.1080/14786419.2014.952234

4. Rawalpally, T. A., Pantothenic acid, in Kroschwitz, J. I. and Howe-Grant, M. (Eds.), Encyclopedia of Chemical Technology, $4^{\text {th }}$ Edition, John Wiley \& Sons Inc., New-York, 2001, pp. 623-624.

5. Kawabata, Y., Demain, A. L., Enzymatic synthesis of pantothenic acid by Escherichia coli cells, in Weetall, H. H. (Ed.), Enzyme Engineering, Plenum Press, New York, 1980, pp. 133-137. doi: http://dx.doi.org/10.1007/978-1-4684-3749-2_63

6. Martinez-Toledo, M. V., Rodelas, B., Salmeron, V., Pozo, C., Gonzales-Lopez, J., Production of pantothenic acid and thiamine by Azotobacter vinelandii in a chemically defined medium and a dialysed soil medium, Biol. Fert. Soils 22 (1996) 131.

doi: http://dx.doi.org/10.1007/BF00384444

7. Drauz, K., Groger, H., May, O., Enzyme Catalysis in Organic Synthesis, $3^{\text {rd }}$ Edition, Wiley-VCH, Weinheim, 2012. doi: http://dx.doi.org/10.1002/9783527639861

8. Zhdanovich, E. S., Kozlova, G. S., Kibalova, N. Y., Isolation and purification of D-pantothenic acid by an ion-exchange method, Pharm. Chem. J. 4 (1970) 85. doi: http://dx.doi.org/10.1007/BF00760119

9. Moiseenok, A. G., Gurinovich, V. A., Lysenkova, V. A., Separation of pantothenic acid derivatives as precursors for the biosynthesis of the acetylation coenzyme by chromatography on DEAE-cellulose, Chem. Nat. Compd. 23 (1987) 216. doi: http://dx.doi.org/10.1007/BF00598762

10. Hudson, T. J., Allen, R. J., Determination of pantothenic acid in multivitamin pharmaceutical preparations by reverse-phase high-performance liquid chromatography, J. Pharm. Sci. 73 (1984) 113. doi: http://dx.doi.org/10.1002/jps.2600730130

11. Haynes, W. M., CRC Handbook of Chemistry and Physics, 93 ${ }^{\text {rd }}$ Edition, CRC Press, Boca Florida, 2012-2013.
12. Caşcaval, D., Kloetzer, L., Galaction, A. I., Influence of organic phase polarity on interfacial mechanism and efficiency of reactive extraction of acetic acid with tri-n-octylamine, J. Chem. Eng. Data 56 (2011) 2521. doi: http://dx.doi.org/10.1021/je200044y

13. Uslu, H., Datta, D., Bamufleh, H. S., Extraction Equilibria of Gibberellic Acid by Tridodecylamine Dissolved in Alcohols, J. Chem. Eng. Data 59 (2013) 3882. doi: http://dx.doi.org/10.1021/je500773w

14. Caşcaval, D., Kloetzer, L., Galaction, A. I., Vlysidis, A., $W e b b, C$., Fractionation of carboxylic acids mixtures obtained by succinic fermentation using reactive extraction, Sep. Sci. Technol. 48 (2013) 634. doi: http://dx.doi.org/10.1080/01496395.2012.691593

15. Caşcaval, D., Galaction, A. I., Kloetzer, L., Synergic extraction of folic acid with di(2-ethylhexyl) phosphoric acid and Amberlite LA-2, Sep. Sci. Technol. 47 (2012) 834. doi: http://dx.doi.org/10.1080/01496395.2011.630056

16. Poştaru, M., Kloetzer, L., Galaction, A. I., Blaga, A. C., Caşcaval, D., Comparative study on rosmarinic acid separation by reactive extraction with Amberlite LA-2 and D2EHPA. 1. Interfacial reaction mechanism and influencing factors, Ind. Eng. Chem. Res. 52 (2013) 13785. doi: http://dx.doi.org/10.1021/ie4023513

17. Schugerl, K., Solvent Extraction in Biotechnology, Springer-Verlag, Berlin, 1994. doi: http://dx.doi.org/10.1007/978-3-662-03064-6

18. Blaga, A. C., Galaction, A. I., Cascaval, D., Separation of amino acids from their mixture by facilitated pertraction with D2EHPA, Chem. Biochem. Eng. Quart. 22 (2008) 439.

19. Galaction, A. I., Caşcaval, D., Nicuță, N., Selective removal of Gentamicin $\mathrm{C}_{1}$ from biosynthetic Gentamicins by facilitated pertraction for increasing antibiotic activity, Biochem. Eng. J. 42 (2008) 28. doi: http://dx.doi.org/10.1016/j.bej.2008.05.005

20. Poştaru, M., Kloetzer, L., Blaga, A. C., Turnea, M., Caşcaval, D., Galaction, A. I., Study on the chemical inactivation of pantothenic acid (vitamin B5), Rom. Biotechnol. Lett. (2016) in press. 